Running Head: Bullying and Supervisor Support

\title{
Bullying, Supervisor Support, Relaxation, and Personal and Work Outcomes: Testing a Moderated Mediation Model
}

Nicolas Gillet

EE 1901 QualiPsy, Université de Tours, Tours, France Institut Universitaire de France (IUF)

Claude Fernet

Département de gestion des ressources humaines, Université du Québec à Trois-Rivières,

Trois-Rivières, Québec, Canada

Philippe Colombat

EE 1901 QualiPsy, Université de Tours, Tours, France

Pierre Cheyroux

EE 1901 QualiPsy, Université de Tours, Tours, France

Evelyne Fouquereau

EE 1901 QualiPsy, Université de Tours, Tours, France

\section{Corresponding author:}

Nicolas Gillet,

Université de Tours,

Faculté Arts et Sciences Humaines,

Département de psychologie,

3 rue des Tanneurs, 37041 Tours Cedex 1, France

E-mail: nicolas.gillet@univ-tours.fr

This is the prepublication version of the following manuscript:

Gillet, N., Fernet, C., Colombat, P., Cheyroux, P., \& Fouquereau, E. (in press). Bullying, supervisor support, relaxation, and personal and work outcomes: Testing a moderated mediation model. Journal of Nursing Management. Early view. https://doi.org/10.1111/jonm.13330

(C) 2021. This paper is not the copy of record and may not exactly replicate the authoritative document published in Journal of Nursing Management. 


\begin{abstract}
Aim: To test a mediated moderation model in which bullying and supervisor support interact to predict nurses' personal and work outcomes with relaxation during off-job time mediating these effects.

Background: Bullying is a pervasive problem in the nursing profession. We integrate and extend past research addressing the question of how bullying and perceived supervisor support affect nurses' functioning.

Method: Cross-sectional data were collected from a sample of 290 nurses who completed measures of bullying, perceived supervisor support, relaxation, need for recovery, sleeping problems, job satisfaction, emotional exhaustion, and work performance.

Results: Results revealed that bullying was significantly linked to job satisfaction, sleeping problems, need for recovery, and emotional exhaustion through relaxation, but only among nurses who perceived high levels of supervisor support.

Conclusion: These results revealed that high supervisor support may be detrimental for nurses adding up to a negative cycle of stressors to maladaptive outcomes through lack of relaxation. Implications for Nursing Management: Healthcare organizations and managers should consider addressing work environment factors, such as bullying, in addition to supervisor support in their efforts to facilitate the positive effects of nurses' relaxation during non-work time.
\end{abstract}

Keywords: Bullying; supervisor support; mediation; moderation; recovery experiences; nurses' functioning 


\section{Introduction}

Bullying is associated with detrimental outcomes because when confronted with such mistreatment, nurses have to regulate their emotions (Goussinsky \& Livne, 2016). Bullying may also influence nurses' functioning through relaxation during off-job hours (Gillet et al., 2020). We propose that bullying makes relaxation during off-job time less likely which in turn will be related positively to sleeping problems, emotional exhaustion, and need for recovery, and negatively to work performance and job satisfaction (Bennett et al., 2018). Another factor relevant for relaxation during non-work refers to supervisor support (Caesens et al., 2014). Therefore, we investigated the links between nurses' perceptions of supervisor support, bullying, relaxation, and personal and professional outcomes (i.e., emotional exhaustion, need for recovery, work performance, sleeping problems, and job satisfaction). More precisely, we examined the indirect effects of bullying on outcomes via relaxation at different levels of perceived supervisor support.

\section{Background}

\section{Direct and Indirect Effects of Bullying and Supervisor Support}

Bullying is a type of mistreatment where the targeted nurse is repeatedly exposed to hostile social acts from others over a prolonged time period (Hoprekstad et al., 2019). Nurses often report that social stressors at work such as bullying intrude into their family lives (Viotti et al., 2018). Past studies have also shown that perceived supervisor support is negatively related to need for recovery and sleeping problems (Saksvik- Lehouillier et al., 2016). Nurses perceive high levels of supervisor support when their supervisors value their contributions and care about their well-being (Caesens et al., 2014). Prior studies found that job demands (stressful work characteristics that cost energy) are detrimental to nurses' behaviors, attitudes, and health, whereas job resources (supportive work characteristics that facilitate goal achievement) are associated with positive outcomes (Huyghebaert et al., 2019).

These effects of perceived supervisor support and bullying may be explained by recovery experiences such as relaxation (Bennett et al., 2018). Relaxation refers to a feeling of low activation, calm, and peacefulness during off-job hours. It has a "crucial intervening role in the relationship between stressful work characteristics on the one hand, and health, well- being and performance capability on the other hand" (Sonnentag \& Geurts, 2009, p. 2). In other words, relaxation may mediate the effects of work environment factors on outcomes (Bennett et al., 2018).

First, past studies have shown that, contrary to job resources, job demands were associated with lower levels of relaxation during off-job time. For instance, perceived supervisor support was positively related to relaxation, whereas workload and emotional dissonance were negatively linked to relaxation (Gillet et al., 2020). Bullying may spill over into personal life, causing work-family conflicts and strain. This suggests that nurses who face these issues in the workplace could not recover efficiently (Viotti et al., 2018). In contrast, nurses with job resources (e.g., perceived supervisor support) would be better equipped to protect themselves from the strains of additional resource loss, thus leading to higher levels of recovery experiences such as relaxation (Bakker \& Demerouti, 2007). Although, to the best of our knowledge, the effects of bullying on relaxation have not yet been examined in the nursing domain, we expect, in line with previous findings, that bullying and perceived supervisor support would be negatively and positively related to relaxation, respectively. In addition, we expect that bullying, as a harmful social stressor, would be related positively to sleeping problems, emotional exhaustion, and need for recovery, and negatively to work performance and job satisfaction. Conversely, perceived supervisor support should have the opposite effects on these outcomes.

Second, relaxation during off-job time allows resources to return to their baseline levels by reducing nurses' activation of their psychophysiological system or related to the 
work area (Meijman \& Mulder, 1998; Sonnentag \& Fritz, 2015). Not surprisingly, relaxation has thus been linked negatively to sleeping problems, emotional exhaustion, and need for recovery, and positively to work performance and job satisfaction (for a review, see Bennett et al., 2018).

Third and finally, the impact of perceived supervisor support and bullying on outcomes should be partially mediated by relaxation (Bennett et al., 2018). Indeed, nurses with adequate job resources (e.g., perceived supervisor support) and demands (e.g., bullying) are more likely to experience recovery (e.g., relaxation) after work, which translates into favorable personal and professional outcomes (e.g., less sleeping problems, better work performance) (Sonnentag \& Fritz, 2015). Numerous studies confirmed this mediating role of relaxation (e.g., Gillet et al., 2020). Consistent with Kinnunen et al.'s (2011) findings, we propose a partial mediation model because job resources and demands have direct effects on outcomes as postulated by Bakker and Demerouti (2007).

\section{The Interactive Effects between Bullying and Supervisor Support}

Prior research has consistently positioned supervisor support as a positive driver of work-related outcomes in a "the more, the better" perspective (Caesens et al., 2014). However, recent findings propose a more nuanced view in which too high levels of supervisor support may be detrimental (Caesens et al., 2020; Gillet et al., 2017). This "too much of a good thing" interpretation is aligned with past results revealing curvilinear relations between social support and employees' outcomes (e.g., affective organizational commitment, trust, inrole performance) (Harris \& Kacmar, 2018). These investigations have demonstrated that the most adaptive outcomes were predicted by moderate to moderately high levels of social support.

Likewise, some scholars also found that higher perceived social support may exacerbate the adverse effects of abusive supervision on employees' burnout (Wu \& $\mathrm{Hu}$, 2009). Indeed, supervisor support may remind nurses of negative aspects of the work environment, and this reminder may aggravate the discomfort by facilitating their reliving and wallowing in the negativity ( $\mathrm{Wu} \& \mathrm{Hu}, 2009)$. The within-domain exacerbation phenomenon also suggests exposure to a work environment that is seen as being both stressful (i.e., bullying) and supportive (i.e., supervisor support) should be more harmful for nurses than exposure to an environment consistently perceived as a source of stress (Major et al., 1997). Supervisors' undermining behaviors tended to be more negatively related to subordinates' levels of well-being, when supervisors were simultaneously perceived as supportive (Duffy et al., 2002). Exposure to supervisors seen as both undermining and supportive was also related to higher job-strain and lower perceived health (Nahum-Shani et al., 2014).

According to the uncertainty management theory, individuals long for certainty about their place in society or a particular community (van den Bos \& Lind, 2002). For nurses, uncertainty may arise when they have difficulty to predict their environment or face inconsistent cognitions, behaviors, or experiences. Therefore, the uncertainty mechanism suggests that exposure to a work environment combining high bullying and high supervisor support should be more stressful and harmful than exposure to a consistently constraining environment (i.e., high bullying and low supervisor support). As a result of being exposed to an inconsistent and hard to anticipate work environment, nurses may feel a sense of loss of control (van den Bos \& Lind, 2002). This perceived lack of control is likely to act as an important stressor for exposed nurses. In addition, mixed messages can thwart nurses' need to experience a coherent sense of self, leading to feelings of self-uncertainty (van den Bos \& Lind, 2002), that could further impede relaxation during off-job time.

\section{Study Aims and Hypotheses}

This study investigated the indirect effects of perceived supervisor support and bullying on nurses' work performance, job satisfaction, emotional exhaustion, sleeping 
problems, and need for recovery through relaxation. In addition, we investigated the interaction effects between bullying and perceived supervisor support in the prediction of relaxation. Thus, the indirect effects of bullying on outcomes via relaxation, at different levels of perceived supervisor support, were examined. Based on the above-stated arguments and research evidence, we formulate the following hypotheses.

Hypothesis 1. Bullying is positively related to sleeping problems, emotional exhaustion, and need for recovery, and negatively related to work performance and job satisfaction.

Hypothesis 2. Perceived supervisor support is negatively related to sleeping problems, emotional exhaustion, and need for recovery, and positively related to work performance and job satisfaction.

Hypothesis 3. Relaxation is negatively related to sleeping problems, emotional exhaustion, and need for recovery, and positively related to job satisfaction and work performance.

Hypothesis 4. The impact of perceived supervisor support and bullying on personal and professional outcomes is partially mediated by relaxation.

Hypothesis 5. Nurses perceiving higher bullying and supervisor support should experience less relaxation than those perceiving higher bullying and lower supervisor support.

Hypothesis 6. The positive impact of bullying on need for recovery, sleeping problems, and emotional exhaustion via relaxation is stronger at high levels of perceived supervisor support.

Hypothesis 7. The negative impact of bullying on job satisfaction and performance via relaxation is stronger at high levels of perceived supervisor support.

\section{Procedure and Sample}

\section{Method}

Data was collected from French nurses and assistant nurses who were approached using social networks in 2019-2020. All potential participants received a survey packet including the questionnaire, a cover letter explaining the study's purposes, and a consent form in which the anonymous and voluntary nature of their participation was emphasized. More precisely, participants were asked to complete a written informed consent form before answering the questionnaire survey. They were also asked to keep their questionnaire anonymous and ensured that information obtained from and about them will not improperly divulged. All participants who agreed to participate then completed an online questionnaire. Questionnaires required approximately 10 minutes to complete. No incentive was offered to take part in the study.

These actions resulted in a heterogeneous convenience sample of nurses. A total of 290 French nurses $(\mathrm{n}=120)$ and assistant nurses $(\mathrm{n}=170)$ with an average age of 36.54 years $(\mathrm{SD}=$ $11.56)$ and 8.17 years $(\mathrm{SD}=9.06)$ of organizational tenure participated to the current research. The majority of nurses $(77.59 \%$ ) held a permanent position, of which $87.93 \%$ were full-time. They were mostly women (98.28\%) and a half of them worked in a public hospital. The adequacy of the sample size was confirmed through power analysis with the following parameters: An anticipated effect size of 0.3 , a desired statistical power of 0.95 , seven latent variables (i.e., bullying, supervisor support, the interaction between bullying and supervisor support, relaxation, sleeping difficulties, emotional exhaustion, and need for recovery), 27 observed variables (four items for bullying, four items for supervisor support, four items for relaxation, four items for sleeping difficulties, five items for emotional exhaustion, four items for need for recovery, one item for job satisfaction, and one item for work performance), and an alpha level of 0.05 . The power analysis indicated 247 to be the minimum appropriate sample size.

\section{Measures}

Bullying. Four items ( $\alpha=.83$; e.g., "Been ignored or excluded") adapted from the Short Negative Acts Questionnaire (Hoprekstad et al., 2019) were used to assess bullying. Participants 
indicated how often they experienced each behavior in the last six months on a five-point scale ranging from 1 (never) to 5 (daily).

Perceived supervisor support. Four items ( $\alpha=.81$; e.g., "My supervisor really cares about my well-being") developed by Caesens et al. (2014) were used to assess perceived supervisor support. Each item was rated on a seven-point scale from 1 (strongly disagree) to 7 (strongly agree).

Relaxation. Four items ( $\alpha=.81$; e.g., "In the evening, after work, and when I am on a weekend/vacation, I do relaxing things") from Sonnentag and Fritz (2007) were used to assess relaxation. All items were rated on a five-point scale from 1 (totally disagree) to 5 (totally agree).

Sleeping difficulties. Four items $(\alpha=.87)$ developed by Jenkins et al. (1988) were used to assess sleeping difficulties over the past four weeks. Each item (e.g., "difficulty falling asleep") was rated on a six-point scale from 1 (not all all) to 6 (22 to 28 days).

Emotional exhaustion. Five items ( $\alpha=.89$; e.g., "I feel emotionally drained by my work") from the Maslach Burnout Inventory-General Survey (Schaufeli et al., 1996) were used to assess emotional exhaustion. Each item was rated on a five-point scale from 1 (strongly disagree) to 5 (strongly agree).

Need for recovery. Using the four items proposed by Xanthopoulou et al. (2018), nurses indicated how often they experienced each feeling $(\alpha=.80$; e.g., "Often, after a day's work I feel so tired that I cannot get involved in other activities") on a four-point scale (1-never to 4-always)

Job satisfaction. A one-item measure (Shimazu et al., 2015; i.e., "Are you satisfied with your job?") was used to assess job satisfaction. Responses were indicated on a four-point scale from 1 (dissatisfied) to 4 (satisfied).

Work performance. A one-item measure ("How would you rate your overall job performance on the days you worked during the past four weeks") was used to assess work performance (Kessler et al., 2003). Performance was rated on a 10-point scale from 0 (worst performance) to 10 (best performance).

\section{Analyses}

We used Mplus 8.4 (Muthén \& Muthén, 2019) with robust maximum likelihood estimator (MLR) to estimate all models. First, we performed a Structural Equation Modeling (SEM) predictive model wherein perceived bullying and supervisor support had direct effects on job satisfaction, sleeping difficulties, need for recovery, emotional exhaustion, and performance, and indirect effects on these outcomes through relaxation. Because fit indices are not available when assessing latent interactions, we used this model to confirm that it provides a satisfactory data representation. Then, latent interactions were estimated with the latent moderated SEM approach (LMS), directly providing the standardized effects (Marsh et al., 2013). Significant interactions were plotted and slope differences tested (Hayes \& Preacher, 2013). This allowed us to examine the influence of bullying at low and high levels of supervisor support.

\section{Results}

The fit indices of the predictive model were satisfactory $\left(\chi^{2}=547.303, \mathrm{df}=297 ; \mathrm{CFI}=\right.$ .93 ; TLI $=.92$; RMSEA $=.05)$. Estimates of the parameters of the measurement model are reported in Table 1, along with the latent correlations in Table 2. Results showed well-defined, reliable, and related but differentiated constructs. They also revealed that bullying was negatively related to relaxation and work performance (see Table 3). They provide partial support for Hypothesis 1. In contrast, supervisor support was positively related to job satisfaction, relaxation, and work performance, and negatively related to need for recovery, sleeping difficulties, and emotional exhaustion. These findings provide support for Hypothesis 2. Moreover, relaxation was negatively related to need for recovery, sleeping difficulties, and emotional exhaustion, and positively related to work performance and job satisfaction, supporting Hypothesis 3 . More generally, bullying had direct and indirect effects (through relaxation) on work performance, whereas supervisor had direct and indirect effects (through relaxation) on job satisfaction, work 
performance, need for recovery, sleeping difficulties, and emotional exhaustion. These findings partially support Hypothesis 4.

Supervisor support and bullying also interacted in the prediction of relaxation. More specifically, supervisor support amplified the negative effects of bullying on relaxation such that the link was stronger when supervisor support was high relative to low (see Table 3 and Figure 1). These results support Hypothesis 5. Finally, the conditional indirect effects of bullying on: a) sleeping difficulties $(\mathrm{b}=.012, \mathrm{p}=.437$; and $\mathrm{b}=.079, \mathrm{p}<.05)$, need for recovery $(\mathrm{b}=.016, \mathrm{p}=$ $.426 ; \mathrm{b}=.110, \mathrm{p}<.01)$, and emotional exhaustion $(\mathrm{b}=.020, \mathrm{p}=.419 ; \mathrm{b}=.134, \mathrm{p}<.01)$ through relaxation were non-significant in the low supervisor support condition and significant and positive in the high supervisor support condition, respectively; b) work satisfaction through relaxation were non-significant at low levels of supervisor support $(b=-.009, p=.420)$ and significant and negative at high levels of supervisor support $(b=-.057, p<.05)$; and $c)$ job performance through relaxation were non-significant in the high $(b=-.081, p=.09)$ and low $(b=$ $-.012, \mathrm{p}=.453$ ) supervisor support conditions. These results partially support Hypothesis 6.

\section{Discussion}

This study investigated different adjustment pathways through which bullying and perceived supervisor act on nurses' functioning. Specifically, we examined whether bullying and perceived supervisor support directly and indirectly (through relaxation during off-time) influence work performance, sleeping difficulties, job satisfaction, emotional exhaustion, and need for recovery. Moreover, we investigate the effects of bullying on relaxation at different levels of perceived supervisor support.

\section{Theoretical Implications}

First, the present study confirms that perceived supervisor support and bullying had positive and negative effects on relaxation during off-job hours, respectively. To the best of our knowledge, these results are the first to show the negative effects of bullying on nurses' relaxation during off-job time. This is particularly interesting as prior research has emphasized the necessity to explore the negative effects of bullying, which is linked to productivity loss, health decline, and unfavorable job attitudes (Serafin et al., 2020). In addition, relaxation was related negatively to need for recovery, sleeping difficulties, and emotional exhaustion, and positively to job satisfaction and work performance. Because relaxation allows to recuperate from stressful aspects of their work- (Sonnentag \& Geurts, 2009), nurses may experience positive outcomes. More generally, the impact of bullying and perceived supervisor support on these outcomes was mediated by relaxation. These results are congruent with those demonstrating the negative influence of bullying, the positive impact of perceived supervisor support, and the mediation of relaxation (Bakker \& Demerouti, 2007; Bennett et al., 2018).

It is noteworthy that perceived supervisor support had also direct effects on sleeping difficulties, need for recovery, emotional exhaustion, job satisfaction, and work performance (Caesens et al., 2020). Thus, the relationship between perceived supervisor support and outcomes was partially mediated by relaxation (Kinnunen et al., 2011). In contrast, and contrary to our expectations, relaxation fully mediated the impact of bullying on job satisfaction, emotional exhaustion, sleeping difficulties, and need for recovery. More generally, these findings show that relaxation may explain the influence of bullying on emotional exhaustion, sleeping difficulties, job satisfaction, and need for recovery (Bennett et al., 2018; Gillet et al., 2020). Because relaxation did not explain the effects of bullying on work performance, future research should consider additional mediating variables such as other recovery experiences (e.g., psychological detachment), emotional labor, or organizational justice (Goussinsky \& Livne, 2016).

Second, the detrimental effect of bullying on relaxation was stronger when supervisor support is high. Interestingly, Wu and $\mathrm{Hu}$ (2009) also demonstrated that higher perceived 
social support exacerbated the adverse influence of abusive supervision on employees' burnout. Indeed, according to the within-domain exacerbation phenomenon, exposure to a work environment characterized by both high bullying and supervisor support is more detrimental for nurses than the combination of low supervisor support and high bullying (Major et al., 1997). According to van den Bos and Lind (2002), this is because nurses may feel a sense of loss of control over their work environment when they are exposed to an inconsistent and hard to anticipate work environment.

Finally, and more generally, the current results showed that the indirect positive influence of bullying on emotional exhaustion, sleeping difficulties, and need for recovery through relaxation only held true for nurses who perceived high levels of supervisor support. This is also the case for the indirect negative effects on job satisfaction. These findings emphasize that having high supervisor support may be detrimental for nurses and does not offer them a beneficial cycle of protective resources to buffer the negative effects of bullying through relaxation. Rather, perceived supervisor support adds up to a negative cycle of stressor to negative outcomes through low relaxation.

\section{Limitations and Research Perspectives}

First, this study made exclusive use of self-report measures, which increases the risk of social desirability and biases responses. Future studies should consider objective measures (e.g., organization data on work performance, biological measures of psychophysiological activation) and ratings of nurses' functioning from a variety of sources (e.g., colleagues, supervisors). Second, we treated covariables as outcomes (e.g., sleeping difficulties, emotional exhaustion) or predictors (i.e., bullying and perceived supervisor support) of relaxation based on theoretical grounds (Sonnentag \& Fritz, 2015). Yet, our cross-sectional findings refrain from drawing conclusion about the directionality of associations. It would therefore be fruitful for future studies to explore the issue of directionality through longitudinal research. Third, French nurses participated in the present study and further research is needed to generalize the current results in different countries and cultures. Finally, bullying, although a serious concern in the nursing profession, was the only job stressor of interest in our research. Yet, it would be interesting to examine how other hindrance (e.g., role conflict, overload, and ambiguity) and challenge demands (e.g., role responsibility and complexity) relate to relaxation, and their interplay with supervisors' interpersonal behaviors.

\section{Implications for Nursing Management}

First, our findings highlight the importance of intervening to maximally reduce exposure to hindrance demands such as workplace bullying. Interventions already exist that can be used to this end. For instance, third-party interventions can individualize allegations of bullying or other forms of mistreatment thereby allow a better understanding of the experiences of targets by reflecting their suffering (Mawdsley \& Thirlwall, 2019). Salin et al. (2020) also showed that policies and training are significant means to reduce bullying across countries. However, numerous national differences are liable to explain preferences for either reconciliatory or disciplinary approaches to prevent bullying. For instance, reconciliation was favored primarily in Austria and Finland. Furthermore, Saam (2010) demonstrated that mediation is inappropriate to reduce workplace bullying since parties involved in workplace bullying (e.g., supervisors and nurses) cannot fairly negotiate with each other. In contrast, at the group level, coaching is suitable because bystanders are able to eliminate the predictors and outcomes of bullying.

Second, managers should be extremely attentive to nurses exposed to, or rather perceiving being exposed to, low levels of support at work, and even more importantly low levels of supervisor support. Indeed, these nurses may experience low relaxation and detrimental outcomes. Consequently, changes designed to increase supervisor support sustainably might facilitate nurses' functioning in the long run, especially if the work environment is not a fertile ground for bullying. For instance, supervisors might promote 
fairness in the application of policies to reinforce the supportive culture. Social events and informal mentoring activities might also be used (Newman et al., 2012). These are means to create positive and supportive relationships between colleagues, subordinates, and supervisors (Newman et al., 2012), where bullying is less likely to occur.

However, awareness could be raised among supervisors on the risks associated with the provision of social support. Indeed, supervisor support exacerbated the adverse influence of bullying on relaxation such that the link was stronger when supervisor support was high rather relative to low. This suggests that caution is needed when devising interventions seeking to increase supervisor support, as it seems to be able to contribute to push employees beyond normative levels of involvement and performance and into workaholism (Gillet et al., 2017). Comprehensive measures of supervisor support might be used to increase supervisors' awareness of their behaviors, and supervisors with problematic profiles (e.g., exposing nurses to hostile social acts while at the same time being supportive) should have access to support (i.e., coaching or training) to help them avoid inconsistency or destructiveness. Additionally, as more and more organizations use weekly and monthly survey platforms, these communication tools could be used to offer quick corrective feedback to supervisors about their behaviors.

Finally, and more generally, our results suggested that efficient ways to achieve work recovery can be developed and trained. Interestingly, approaches to successful train work recovery have been proposed, and validated in previous studies. For instance, participants involved in a recovery training program (e.g., time management techniques, self-reflection) were characterized by better recovery experiences (e.g., relaxation) and higher levels of sleep quality after the training, in comparison to those not involved in this training (Hahn et al., 2011). Mindfulness-based interventions are also useful to increase relaxation during off-job time (Turow, 2017).

\section{Conclusion}

The research emphasizes that relaxation during off-job time not only depends on bullying but also on supervisor support. Therefore, the strategies that could be deployed to increase relaxation and its beneficial consequences (i.e., higher levels of work performance and job satisfaction, and lower levels of emotional exhaustion, sleeping difficulties, and need for recovery) are twofold. 


\section{References}

Bakker, A. B., \& Demerouti, E. (2007). The Job Demands-Resources model: State of the art. Journal of Managerial Psychology, 22, 309-328. https://doi.org/10.1108/02683940710733115

Bennett, A. A., Bakker, A. B., \& Field, J. G. (2018). Recovery from work- related effort: A meta- analysis. Journal of Organizational Behavior, 39, 262-275. https://doi.org/10.1002/job.2217

Caesens, G., Gillet, N., Morin, A. J. S., Houle, S. A., \& Stinglhamber, F. (2020). A person- centred perspective on social support in the workplace. Applied Psychology: An International Review, 69, 686-714. https://doi.org/10.1111/apps.12196

Caesens, G., Stinglhamber, F., \& Luypaert, G. (2014). The impact of work engagement and workaholism on well-being: The role of work-related social support. The Career Development International, 19, 813-835. https://doi.org/10.1108/CDI-09-2013-0114

Duffy, M. K., Ganster, D., \& Pagon, M. (2002). Social undermining in the workplace. Academy of Management Journal, 45, 331-351. https://doi.org/10.2307/3069350

Gillet, N., Huyghebaert-Zouaghi, T., Réveillère, C., Colombat, P., \& Fouquereau, E. (2020). The effects of job demands on nurses' burnout and presenteeism through sleep quality and relaxation. Journal of Clinical Nursing, 29, 583-592. https://doi.org/10.1111/jocn.15116

Gillet, N., Morin, A. J. S., Cougot, B., \& Gagné, M. (2017). Workaholism profiles: Associations with determinants, correlates, and outcomes. Journal of Occupational and Organizational Psychology, 90, 559-586. https://doi.org/10.1111/joop.12185

Goussinsky, R., \& Livne, Y. (2016). Coping with interpersonal mistreatment: The role of emotion regulation strategies and supervisor support. Journal of Nursing Management, 24, 1109-1118. https://doi.org/10.1111/jonm.12415

Hahn, V. C., Binnewies, C., Sonnentag, S., \& Mojza, E. J. (2011). Learning how to recover from job stress: Effects of a recovery training program on recovery, recovery-related selfefficacy, and well-being. Journal of Occupational Health Psychology, 16, 202-216. https://doi.org/10.1037/a0022169

Harris, K. J., \& Kacmar, K. M. (2018). Is more always better? An examination of the nonlinear effects of perceived organizational support on individual outcomes. The Journal of Social Psychology, 158, 187-200. https://doi.org/10.1080/00224545.2017.1324394

Hayes, A. F., \& Preacher, K. J. (2013). Conditional process modeling: Using structural equation modeling to examine contingent causal processes. In G. R. Hancock \& R. O. Mueller (Eds.), Quantitative methods in education and the behavioral sciences: Issues, research, and teaching. Structural equation modeling: A second course (pp. 219-266). IAP Information Age Publishing.

Hoprekstad, Ø. L., Hetland, J., Bakker, A. B., Olsen, O. K., Espevik, R., Wessel, M., \& Einarsen, S. V. (2019). How long does it last? Prior victimization from workplace bullying moderates the relationship between daily exposure to negative acts and subsequent depressed mood. European Journal of Work and Organizational Psychology, 28, 164178. https://doi.org/10.1080/1359432X.2018.1564279

Huyghebaert, T., Gillet, N., Audusseau, O., \& Fouquereau, E. (2019). Perceived career opportunities, commitment to the supervisor, social isolation: Their effects on nurses' well- being and turnover. Journal of Nursing Management, 27, 207-214. https://doi.org/10.1111/jonm.12666

Jenkins, C., Stanton, B., Niemcryk, S., \& Rose, R. (1988). A scale for the estimation of sleep problems. Journal of Clinical Epidemiology, 41, 313-321. https://doi.org/10.1016/08954356(88)90138-2 
Kessler, R. C., Barber, C., Beck, A., Berglund, P., Cleary, P. D., McKenas, D., Pronk, N., Simon, G., Stang, P., Ustun, T. B., \& Wang, P. (2003). The World Health Organization Health and Work Performance Questionnaire (HPQ). Journal of Occupational and Environmental Medicine, 45, 156-174. https://doi.org/10.1097/01.jom.0000052967.43131.51

Kinnunen, U., Feldt, T., Siltaloppi, M., \& Sonnentag, S. (2011). Job demands-resources model in the context of recovery: Testing recovery experiences as mediators. European Journal of Work and Organizational Psychology, 20, 805-832. https://doi.org/10.1080/1359432X.2010.524411

Major, B., Zubek, J. M., Cooper, M. L., Cozzarelli, C., \& Richards, C. (1997). Mixed messages: Implications of social conflict and social support within close relationships for adjustment to a stressful life event. Journal of Personality and Social Psychology, 72, 1349-1363. https://doi.org/10.1037/0022-3514.72.6.1349

Marsh, H. W., Hau, K.-T., Wen, Z., Nagengast, B., \& Morin, A. J. S. (2013). Moderation. In T. D. Little (Ed.), Oxford library of psychology. The Oxford handbook of quantitative methods: Statistical analysis (pp. 361-386). Oxford University Press.

Mawdsley, H., \& Thirlwall, A. (2019). Third-party interventions in workplace bullying: A neoliberal agenda? Employee Relations, 41, 506-519. https://doi.org/10.1108/ER-092017-0216

Meijman, T. F., \& Mulder, G. (1998). Psychological aspects of workload. In P. J. D. Drenth, H. Thierry, \& C. J. de Wolff (Eds.), Handbook of work and organizational psychology: Work psychology (Vol. 2, pp. 5-33). Psychology Press.

Muthén, L. K., \& Muthén, B. (2019). Mplus user's guide. Muthén \& Muthén.

Nahum-Shani, I., Henderson, M. M., Lim, S., \& Vinokur, A. D. (2014). Supervisor support: Does supervisor support buffer or exacerbate the adverse effects of supervisor undermining? Journal of Applied Psychology, 99, 484-503. https://doi.org/10.1037/a0035313

Newman, A., Thanacoody, R., \& Hui, W. (2012). The effects of perceived organizational support, perceived supervisor support and intra-organizational network resources on turnover intentions: A study of Chinese employees in multinational enterprises. Personnel Review, 41, 56-72. https://doi.org/10.1108/00483481211189947

Saam, N. J. (2010). Interventions in workplace bullying: A multilevel approach. European Journal of Work and Organizational Psychology, 19, 51-75. https://doi.org/10.1080/13594320802651403

Saksvik- Lehouillier, I., Bjorvatn, B., Magerøy, N., \& Pallesen, S. (2016). Hardiness, psychosocial factors and shift work tolerance among nurses - A 2- year follow- up study. Journal of Advanced Nursing, 72, 1800-1812. https://doi.org/10.1111/jan.12951

Salin, D., Cowan, R. L., Adewumi, O., Apospori, E., Bochantin, J., D'Cruz, P., Djurkovic, N., Durniat, K., Escartín, J., Guo, J., Işik, I., Koeszegi, S. T., McCormack, D., Monserrat, S. I., Olivas-Luján, M. R., \& Zedlacher, E. (2020). Prevention of and interventions in workplace bullying: A global study of human resource professionals' reflections on preferred action. The International Journal of Human Resource Management, 31, 26222644. https://doi.org/10.1080/09585192.2018.1460857

Schaufeli, W. B., Leiter, M. P., Maslach, C., \& Jackson, S. E. (1996). The Maslach Burnout Inventory-General Survey. In C. Maslach, S. E. Jackson, \& M. P. Leiter (Eds.), Maslach Burnout Inventory $3^{\text {rd }}$ ed. (pp. 19-26). Consulting Psychologists Press.

Serafin, L., Sak- Dankosky, N., \& Czarkowska- Pączek, B. (2020). Bullying in nursing evaluated by the Negative Acts Questionnaire- Revised: A systematic review and meta- analysis. Journal of Advanced Nursing, 76, 1320-1333. https://doi.org/10.1111/jan.14331 
Shimazu, A., Schaufeli, W. B., Kamiyama, K., \& Kawakami, N. (2015). Workaholism vs. work engagement: The two different predictors of future well-being and performance. International Journal of Behavioral Medicine, 22, 18-23. https://doi.org/10.1007/s12529014-9410-x

Sonnentag, S., \& Fritz, C. (2007). The Recovery Experience Questionnaire: Development and validation of a measure for assessing recuperation and unwinding from work. Journal of Occupational Health Psychology, 12, 204-221. https://doi.org/10.1037/10768998.12.3.204

Sonnentag, S., \& Fritz, C. (2015). Recovery from job stress: The stressor- detachment model as an integrative framework. Journal of Organizational Behavior, 36, S72-S103. https://doi.org/10.1002/job.1924

Sonnentag, S., \& Geurts, S. A. E. (2009). Methodological issues in recovery research. In S. Sonnentag, P. L. Perrewé, \& D. C. Ganster (Eds.), Research in occupational stress and well-being: Vol. 7. Current perspectives on job-stress recovery (pp. 1-46). Emerald Group Publishing Limited. https://doi.org/10.1108/S14793555(2009)0000007004

Turow, R. G. (2017). Mindfulness skills for trauma and PTSD: Practices for recovery and resilience. W. W. Norton \& Co.

van den Bos, K., \& Lind, E. A. (2002). Uncertainty management by means of fairness judgments. In M. P. Zanna (Ed.), Advances in experimental social psychology (Vol. 34, pp. 1-60). Academic Press. https://doi.org/10.1016/S0065-2601(02)80003-X

Viotti, S., Arnetz, J. E., \& Converso, D. (2018). Does bullying affect work-to-private-life interference? Testing the mediating role of resilience. Journal of Aggression, Maltreatment \& Trauma, 27, 409-424. https://doi.org/10.1080/10926771.2017.1422842

Wu, T.-Y., \& Hu, C. (2009). Abusive supervision and employee emotional exhaustion: Dispositional antecedents and boundaries. Group \& Organization Management, 34, 143-169. https://doi.org/10.1177/1059601108331217

Xanthopoulou, D., Bakker, A. B., Oerlemans, W. G. M., \& Koszucka, M. (2018). Need for recovery after emotional labor: Differential effects of daily deep and surface acting. Journal of Organizational Behavior, 39, 481-494. https://doi.org/10.1002/job 


\section{Table 1}

Standardized Factor Loadings ( $\lambda$ ) and Uniquenesses $(\delta)$ for the Variables

\begin{tabular}{|c|c|c|c|c|c|c|c|}
\hline Items & BUL $\lambda$ & $\mathrm{SS} \lambda$ & $\operatorname{REL} \lambda$ & $\mathrm{EE} \lambda$ & $\mathrm{SD} \lambda$ & NFR $\lambda$ & $\delta$ \\
\hline \multicolumn{8}{|l|}{ Bullying } \\
\hline Item 1 & .790 & & & & & & .375 \\
\hline Item 2 & .765 & & & & & & .415 \\
\hline Item 3 & .713 & & & & & & .492 \\
\hline Item 4 & .694 & & & & & & .518 \\
\hline$\omega$ & .830 & & & & & & \\
\hline \multicolumn{8}{|c|}{ Supervisor support } \\
\hline Item 1 & & .889 & & & & & .210 \\
\hline Item 2 & & .429 & & & & & .816 \\
\hline Item 3 & & .880 & & & & & .226 \\
\hline Item 4 & & .531 & & & & & .718 \\
\hline$\omega$ & & .791 & & & & & \\
\hline \multicolumn{8}{|l|}{ Relaxation } \\
\hline Item 1 & & & .682 & & & & .535 \\
\hline Item 2 & & & .912 & & & & .169 \\
\hline Item 3 & & & .938 & & & & .120 \\
\hline Item 4 & & & .701 & & & & .508 \\
\hline$\omega$ & & & .887 & & & & \\
\hline \multicolumn{8}{|c|}{ Emotional exhaustion } \\
\hline Item 1 & & & & .806 & & & .351 \\
\hline Item 2 & & & & .765 & & & .414 \\
\hline Item 3 & & & & .846 & & & .284 \\
\hline Item 4 & & & & .894 & & & .201 \\
\hline Item 5 & & & & .643 & & & .586 \\
\hline$\omega$ & & & & .895 & & & \\
\hline \multicolumn{8}{|c|}{ Sleeping difficulties } \\
\hline Item 1 & & & & & .702 & & .507 \\
\hline Item 2 & & & & & .879 & & .227 \\
\hline Item 3 & & & & & .922 & & .151 \\
\hline Item 4 & & & & & .671 & & .550 \\
\hline$\omega$ & & & & & .875 & & \\
\hline \multicolumn{8}{|c|}{ Need for recovery } \\
\hline Item 1 & & & & & & .676 & .543 \\
\hline Item 2 & & & & & & .702 & .507 \\
\hline Item 3 & & & & & & .729 & .468 \\
\hline Item 4 & & & & & & .700 & .511 \\
\hline$\omega$ & & & & & & .795 & \\
\hline
\end{tabular}

Note. $\lambda$ : Factor loading; $\delta$ : Item uniqueness; $\omega$ : Omega coefficient of model-based composite reliability; BUL: Bullying; SS: Supervisor support; REL: Relaxation; EE: Emotional exhaustion; SD: Sleeping difficulties; NFR: Need for recovery; all parameters are significant $(\mathrm{p}<.05)$. 
Table 2

Latent Correlations between Variables

\begin{tabular}{|c|c|c|c|c|c|c|c|c|}
\hline Variable & 1 & 2 & 3 & 4 & 5 & 6 & 7 & 8 \\
\hline 1. Bullying† & - & & & & & & & \\
\hline 2. Supervisor Support $\dagger$ & -.266 & - & & & & & & \\
\hline 3. Relaxation $\dagger$ & -.225 & .237 & - & & & & & \\
\hline 4. Emotional Exhaustion $\dagger$ & .307 & -.533 & -.512 & - & & & & \\
\hline 5. Sleeping Difficulties $†$ & .265 & -.353 & -.367 & .535 & - & & & \\
\hline 6. Need for Recovery $\dagger$ & .201 & -.372 & -.503 & .712 & .540 & - & & \\
\hline 7. Job Satisfaction & -.234 & .362 & .362 & -.543 & -.313 & -.490 & - & \\
\hline 8. Work Performance & -.339 & .274 & .272 & -.365 & -.212 & -.350 & .407 & - \\
\hline
\end{tabular}

Note. All correlations are significant $(\mathrm{p}<.001) ; \uparrow:$ Factor scores from the preliminary model with a mean of 0 and standard deviation of 1. 


\section{Table 3}

Predictive Results

\begin{tabular}{|c|c|c|c|c|c|c|c|c|c|c|}
\hline \multirow[b]{2}{*}{ Predictors } & \multicolumn{2}{|l|}{ Relaxation } & \multicolumn{2}{|c|}{ Sleeping Difficulties } & \multicolumn{2}{|c|}{ Emotional Exhaustion } & \multicolumn{2}{|c|}{ Need for Recovery } & \multicolumn{2}{|c|}{ Job Satisfaction } \\
\hline & b (s.e.) & $\beta$ & b (s.e.) & $\beta$ & b (s.e.) & $\beta$ & b (s.e.) & $\beta$ & b (s.e.) & $\beta$ \\
\hline \multicolumn{11}{|l|}{ No Interactions } \\
\hline Bullying & $-.133(.060)^{*}$ & -.159 & & & & & & & & \\
\hline & .070 & & & & & & & & & \\
\hline \multicolumn{11}{|l|}{ Interactions } \\
\hline Bullying & $-.227(.076) * *$ & -.246 & & & & & & & & \\
\hline Supervisor Support & $.151(.060)^{*}$ & .164 & & & & & & & & \\
\hline Interaction & $-.168(.059)^{* *}$ & -.182 & & & & & & & & \\
\hline$R^{2}$ & .143 & & & & & & & & & \\
\hline Bullying & & & $.142(.073)$ & .127 & $.139(.082)$ & .108 & $.038(.076)$ & .033 & $-.068(.044)$ & -.099 \\
\hline Supervisor Support & & & $-.261(.079) * *$ & -.234 & $-.490(.089) * *$ & -.381 & $-.263(.088) * *$ & -.227 & $.178(.042)^{* *}$ & .260 \\
\hline Relaxation & & & $-.354(.093) * *$ & -.266 & $-.573(.101)^{* *}$ & -.374 & $-.538(.108)^{* *}$ & -.390 & $.225(.050)^{* *}$ & .275 \\
\hline \multirow[t]{3}{*}{$R^{2}$} & & & .195 & & .394 & & .252 & & .206 & \\
\hline & Work Performa & nce & & & & & & & & \\
\hline & $\mathrm{b}($ s.e. $)$ & $\beta$ & & & & & & & & \\
\hline Supervisor Support & $.325(.130)^{*}$ & .164 & & & & & & & & \\
\hline Relaxation & $.425(.148)^{* *}$ & .180 & & & & & & & & \\
\hline \multirow{3}{*}{$\mathrm{R}^{2}$} & .163 & & & & & & & & & \\
\hline & Relaxation & & & & & & & & & \\
\hline & $\mathrm{a}$ & b (s.e.) & & & & & & & & \\
\hline \multicolumn{11}{|c|}{ Bullying: Simple Slopes } \\
\hline -2SD Supervisor Support & -.302 & $.109(.106)$ & & & & & & & & \\
\hline -1SD Supervisor Support & -.151 & $-.059(.070)$ & & & & & & & & \\
\hline Mean Supervisor Support & 0 & $-.227(.076) * *$ & & & & & & & & \\
\hline 1SD Supervisor Support & .151 & $-.395(.116)^{* *}$ & & & & & & & & \\
\hline 2SD Supervisor Support & .302 & $-.563(.167)^{* *}$ & & & & & & & & \\
\hline
\end{tabular}

Note. $\mathrm{R}^{2}$ : Squared multiple correlation (reflecting the proportion of explained variance); a: Regression intercept (used in drawing the simple slope graphs); $\mathrm{b}$ :

Unstandardized regression coefficient; s.e.: Standard error of the coefficient; $\beta$ : Standardized regression coefficient; SS: Supervisor support; $*$ p < .05; ** $p<.01$. 


\section{Figure 1}

Simple Slope Analysis of the Effects of Bullying at Different Levels of Supervisor Support in the Prediction of Relaxation

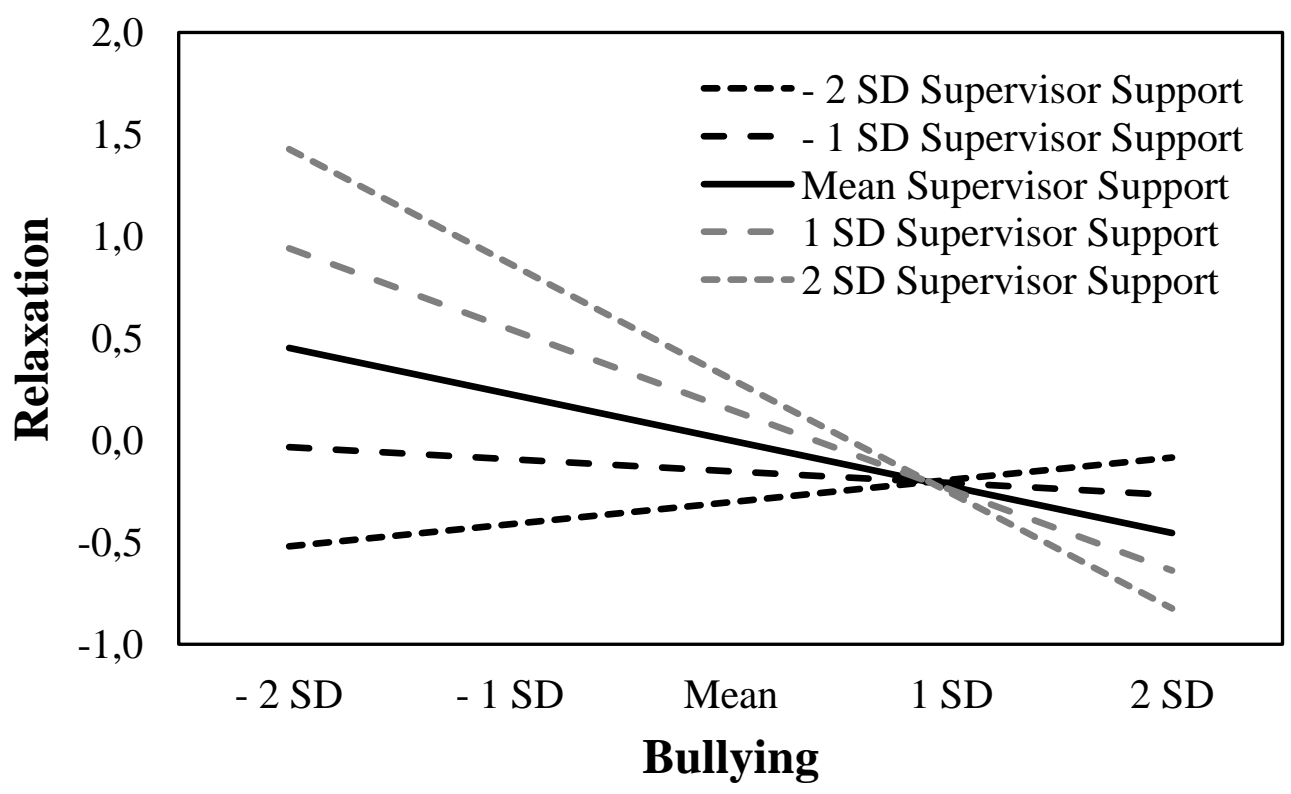

